\title{
Fabrication of a light-emitting device based on the CdS/ZnS spherical quantum dots
}

\author{
Kobra Hasanirokh ${ }^{1 *}$, Asghar Asgari ${ }^{1,2}$ and Saber Mohammadi ${ }^{1}$
}

\begin{abstract}
In this work, we focus on the colloidal quantum dot based light-emitting diodes (QD-LEDs) performance. First, we synthesize the spherical QDs with a CdS core that covered with a wider band gap II-VI semiconductor acting as a shell (ZnS). In order to synthesize this nano crystal QDs with structure of CdS/ZnS/CdS/ZnS, we use a reverse micelle process. These four-layer quantum well quantum dots (QWQDs) can generate the white light emission. The positional design of different layers i.e., core/shell QD emitters is a critical factor for white emissive devices. The blue emission generated by CdS core mixes with green/orange components originating from ZnS inner shell and creates an efficiency white light emission. Then, we fabricate a white-QDLED with a device structure of FTO/ ZnO / $\mathrm{QD} / \mathrm{CBP} / \mathrm{MoO}_{3} / \mathrm{Al}$ films. A thin film of $\mathrm{CdS} / \mathrm{ZnS} / \mathrm{CdS} / \mathrm{ZnS}$ QDs is deposited by electrostatically assembled colloidal QD solutions. The experimental results show that the emission spectra of QDs and current density through the LED are controlled by varying the particle sizes. The peaks of absorbance and Photoluminescence (PL) spectrums for core/shell structures get the red shifted as the dot size increases. Furthermore, this QD-LED with a smaller nano particle layer has a higher current density.
\end{abstract}

Keywords: Colloidal quantum dot, Light-emitting diodes, Photoluminescence, Absorbance, Reverse micelle method, Current density

\section{Introduction}

Recently, QD-LEDs have been extensively investigated due to their unique and fantastic optical properties of colloidal synthesized quantum dots (QDs) [1-4]. QD films exhibit easy color tenability over the entire visible spectrum, broad absorption spectrum and high photoluminescence quantum yield. These attractive properties and advantages make them to be promising for the light emitting applications [5-9]. Solid state white light emitting diodes (WLEDs) as the new generation of light sources can offer the chance to lower thermal resistance and longer lifetime [10, 11].

Group II-VI metal chalcogenide semiconductors specially CdS, CdSe and $\mathrm{ZnS}$ have been of interest because they show high photoluminescence (PL) in the visible

\footnotetext{
* Correspondence: zhasanirokh@yahoo.com

'Research Institute for Applied Physics \& Astronomy, University of Tabriz, Tabriz 51665-163, Iran

Full list of author information is available at the end of the article
}

region. Emission from the QD-LEDs depends strongly on the size of the QDs and their composition [8].

Cadmium compounds QDs arising from the colorsaturated photoluminescence (red, green, blue) have attracted more attention as a good potential utility of the design and fabrication of the QD-based WLEDs. CdS has the best PL and is also widely used in solid state applications [12-15].

$\mathrm{ZnS}$ is another important semiconductor to investigate. It is extensively studied as a luminescent material for optoelectronic application $[5,12]$.

Many different deposition techniques have been utilized to affect device performance and improve the optical properties of LEDs [16-18]. Some authors reported that the core-shell type nanoparticles such as CdSe/ZnS [5] are good candidates for white emission QD- LEDs. In this type of nanostructures that are composed of two different semiconductors, first semiconductor is the core and the second one, with a wider band gap than the core, is the shell.
Springer Open

(c) The Author(s). 2021 Open Access This article is licensed under a Creative Commons Attribution 4.0 International License, which permits use, sharing, adaptation, distribution and reproduction in any medium or format, as long as you give appropriate credit to the original author(s) and the source, provide a link to the Creative Commons licence, and indicate if changes were made. The images or other third party material in this article are included in the article's Creative Commons licence, unless indicated otherwise in a credit line to the material. If material is not included in the article's Creative Commons licence and your intended use is not permitted by statutory regulation or exceeds the permitted use, you will need to obtain permission directly from the copyright holder. To view a copy of this licence, visit http://creativecommons.org/licenses/by/4.0/. 
Enhancing the light- extraction efficiency is one of the key issues for realizing highly efficient LEDs. The experimentally researchers introduced several features to improve this efficiency in AlGaN- based diodes [19]. It has been demonstrated that the bright and efficient QDLEDs fabricated from thin and uniform CdSe/ZnS colloidal QD films show high optical quality [20] and have maximum luminance and current efficiency [5].

This study aimed to investigate experimentally the performance of the QWQD diodes. In the present work, $\mathrm{CdS} / \mathrm{ZnS} / \mathrm{CdS} / \mathrm{ZnS}$ QDs are prepared by a reverse micelle process. In this nano structure, blue emission from $\mathrm{CdS}$ core combines by the green and red emissions from $\mathrm{ZnS}$ inner shell and this recombination products efficiently white light emitting. In the following, we fabricate a deposition of luminescent QDs film by electrostatically assembled colloidal QD solutions. The experimental results have shown that the QDs size can manage the absorbance and PL spectrums. Finally, we investigate the influences of the dot size on the current density and present how this parameter can control the current density through this six layer WLED.

\section{Experimental}

White light emitting diode based on the $\mathrm{CdS} / \mathrm{ZnS} / \mathrm{CdS} /$ $\mathrm{ZnS}$ QDs is prepared by following two synthetic protocols. First, we have to synthesize the colloidal QDs, then we fabricate the a QD-WLED with ITO/ $\mathrm{ZnO} / \mathrm{QD} /$ $\mathrm{CBP} / \mathrm{MoO}_{3} / \mathrm{Al}$ structure.

\section{CdS/ZnS QDS synthesis}

At first, we need solutions of $\mathrm{Cd}\left(\mathrm{CH}_{3} \mathrm{COO}\right)_{2} \cdot 2 \mathrm{H}_{2} \mathrm{O}$, $\mathrm{Na}_{2} \mathrm{~S}$ and $\mathrm{Zn}\left(\mathrm{CH}_{3} \mathrm{COO}\right)_{2}$ precursors in water with concentrations $0.1 \mathrm{M}$ and $0.26 \mathrm{M}$, respectively. Now, we solve the dioctyl sulfosuccinate sodium salt (AOT) in heptane to prepare $0.1 \mathrm{M}$ surfactant solution and then add it to solution of each precursor. It should be mentioned that the volume ratio $W=\frac{\left[\mathrm{H}_{2} \mathrm{O}\right]}{[\mathrm{AOT}]}$ must be the same for $\mathrm{Cd}^{2+}, \mathrm{Zn}^{2+}$ and $\mathrm{S}^{2-}$ solutions. $\mathrm{CdS}$ core is formed after $15-\mathrm{min}$ reaction of $70 \mathrm{cc} \mathrm{S}^{2-}$ with $12 \mathrm{cc}$ $\mathrm{Cd}^{2+}$ micellar stock solutions. In order to generate $\mathrm{CdS} /$ $\mathrm{ZnS}$ core/shell QDs, we slowly add $20 \mathrm{cc} \mathrm{Zn}^{2+}, 12 \mathrm{cc}$ $\mathrm{Cd}^{2+}$ and finally $50 \mathrm{cc} \mathrm{Zn}^{2+}$ solutions to $\mathrm{CdS}$ core [12]. Finally, the resulting QWQDs are washed with heptane and methanol and dispersed in methanol for characterization.

\section{QDLED fabrication}

The FTO-coated glass substrates were cleaned in ultrasonic baths of detergent, de-ionized water, and acetone, then were immediately put it in the oven. After the above cleaning, fabrication of the QD-LEDs starts with a zinc oxide $(\mathrm{ZnO})$ electron-transport layer formation by

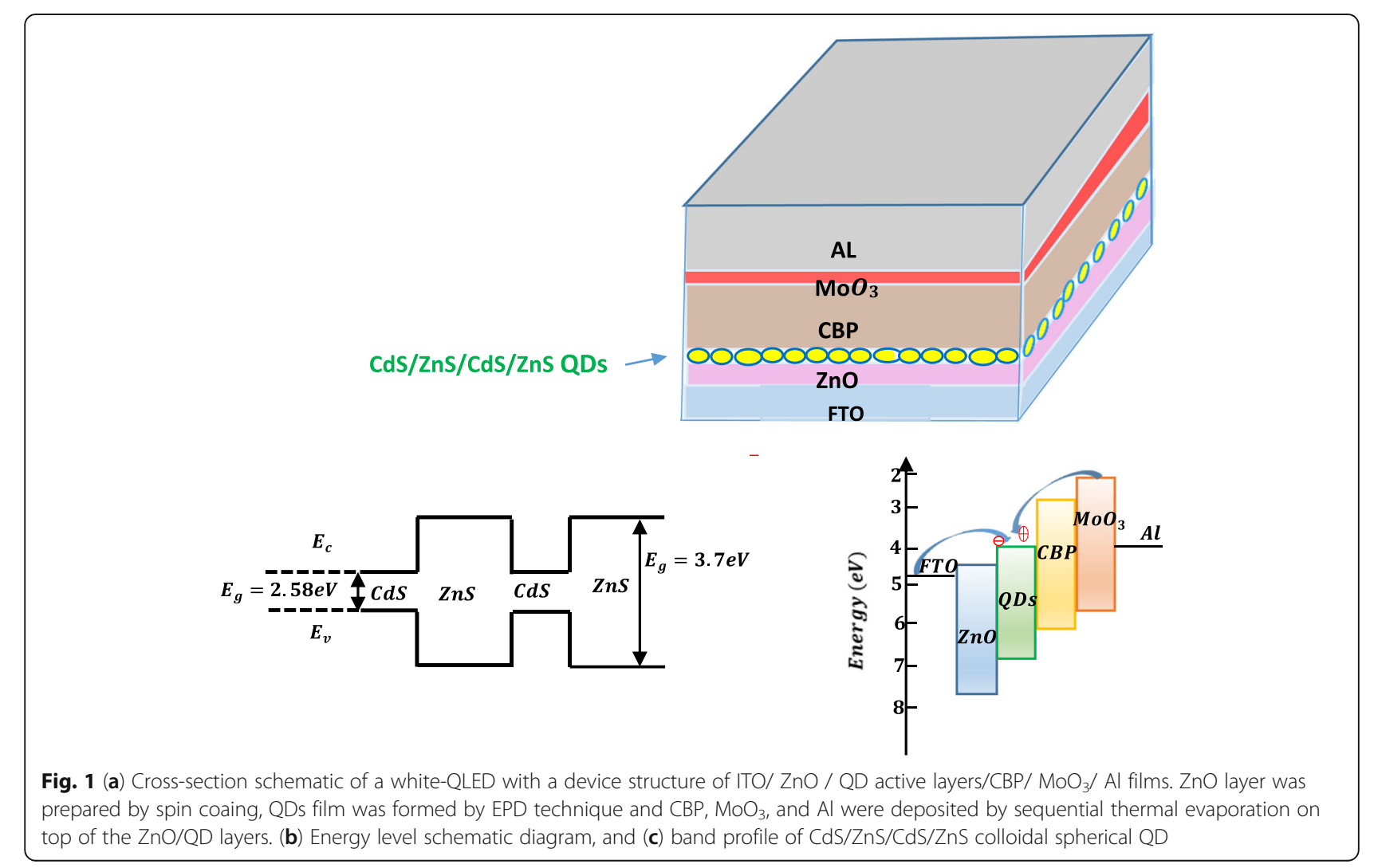


spin-coating method of zinc acetate solution onto the FTO and heating it at $300^{\circ} \mathrm{C}$ for $5 \mathrm{~min}$. Then, a thin QDs film as the emissive layer is electrophoretically deposited in an electrophoretic deposition (EPD) process [21-24]. In EPD procedure, we applied $45 \mathrm{Vcm}^{-1}$ electric field for $5 \mathrm{~min}$ on two $\mathrm{ZnO}$-on-FTO substrates fixed in $4 \mathrm{~mm}$ apart from each other. After that, we transferred the samples into a vacuum chamber to deposit the dicarbazolebiphenyl (CBP) as a hole transporting layer, molybdenum oxide $\left(\mathrm{MoO}_{3}\right)$ as a hole-injection layer, and an aluminum (Al) by sequential thermal evaporation. The same method is described in detail in Ref. [20]. A schematic of the device structure and crosssectional view of the multilayer white-emitting QDLED is shown in Fig. 1.

Our QD-LED structure was designed to reach efficient electron and hole injection from these electrodes to the QDs. We also required to effectively block electrons and holes passing through the QD layer. It is well known that the $\mathrm{ZnO}$ particles is highly advantageous for QLEDs with conventional structures owing to high electron mobility $\left(2 \times 10^{-3} \mathrm{~cm}^{2} \mathrm{~V}^{-1} \mathrm{~s}^{-1}\right)$ and low temperature behavior.

\section{Results and discussion}

The proposed spherically grown QDs composes of two different emitter layers in which each layer can emit specific wavelengths in the visible range (RGB spectrum). In introduced nano structure QD, $\mathrm{CdS}$ as a core is coated by shell $\mathrm{ZnS}$. The core $\mathrm{CdS}$ with band gap $E_{g}=2.58 \mathrm{eV}$ can emit the blue spectrum and shell $\mathrm{ZnS}$ can emit both of the green and red spectrums. Hence, this novel type of QWQD achieves efficiently white light emission. The absorption and photoluminescence spectra were investigated to explore the optical properties of theses QDs. Experimental results have shown that the dot size has central role in control of the output light properties.

The absorbance spectrums of WLED at different time after the synthesis are shown in Fig. 2. The water-tosurfactant molar ratio is $\mathrm{W}=5$. The absorbance spectrums show two peaks centered at $\lambda \cong 486 \mathrm{~nm}$ for core $\mathrm{CdS}$ and $\lambda \cong 525 \mathrm{~nm}$ for core $/ \mathrm{shell} \mathrm{CdS} / \mathrm{ZnS}$ that exhibit
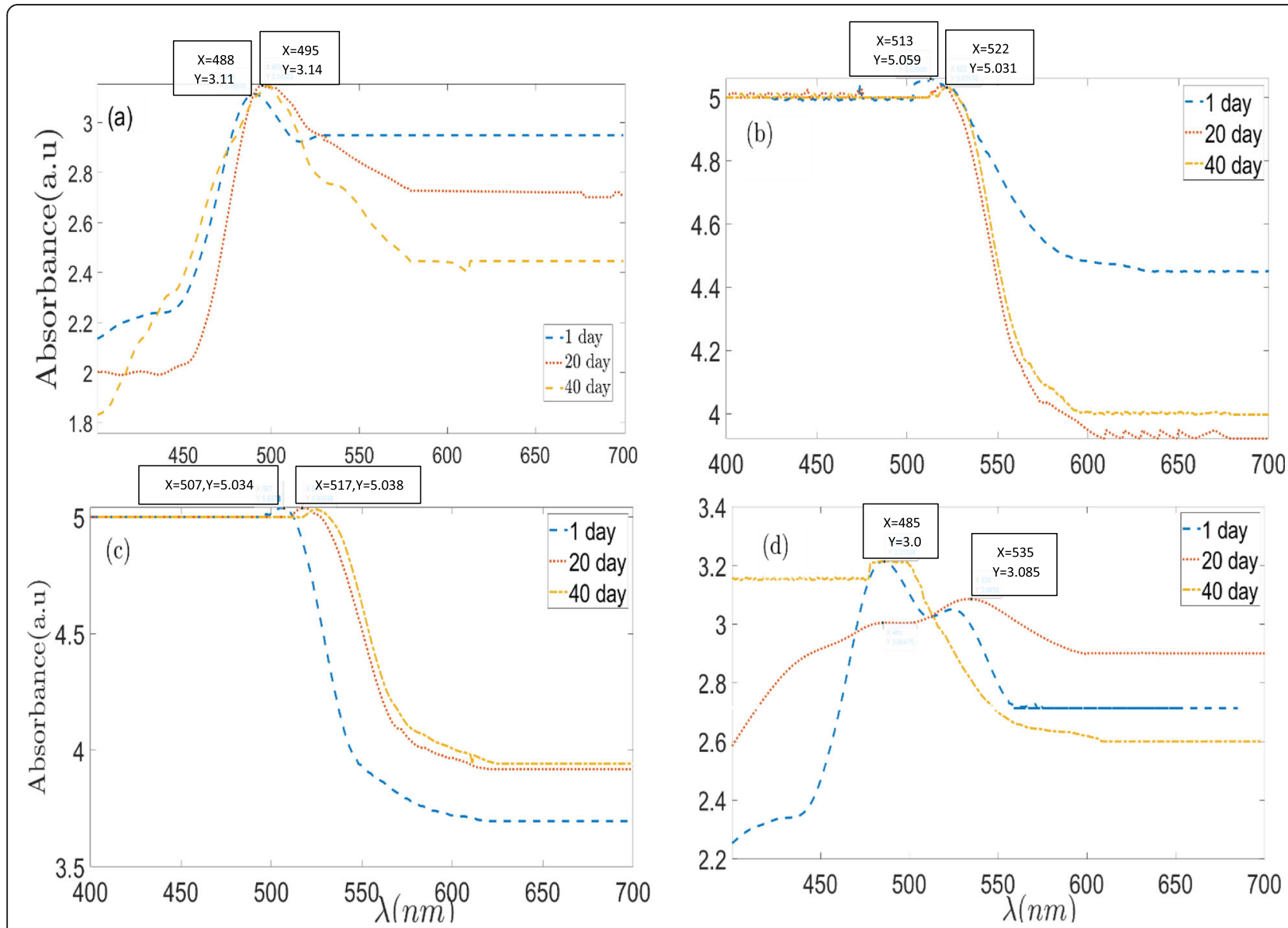

Fig. 2 Time evolution of QWQDs absorbance spectrum for a) core $(d S$, b) core/shell CdS/ZnS, C) CdS/ZnS/CdS, and d) white light emitting CdS/ $\mathrm{ZnS} / \mathrm{CdS} / \mathrm{ZnS}$. Here we assume that $\mathrm{W}=5$ 

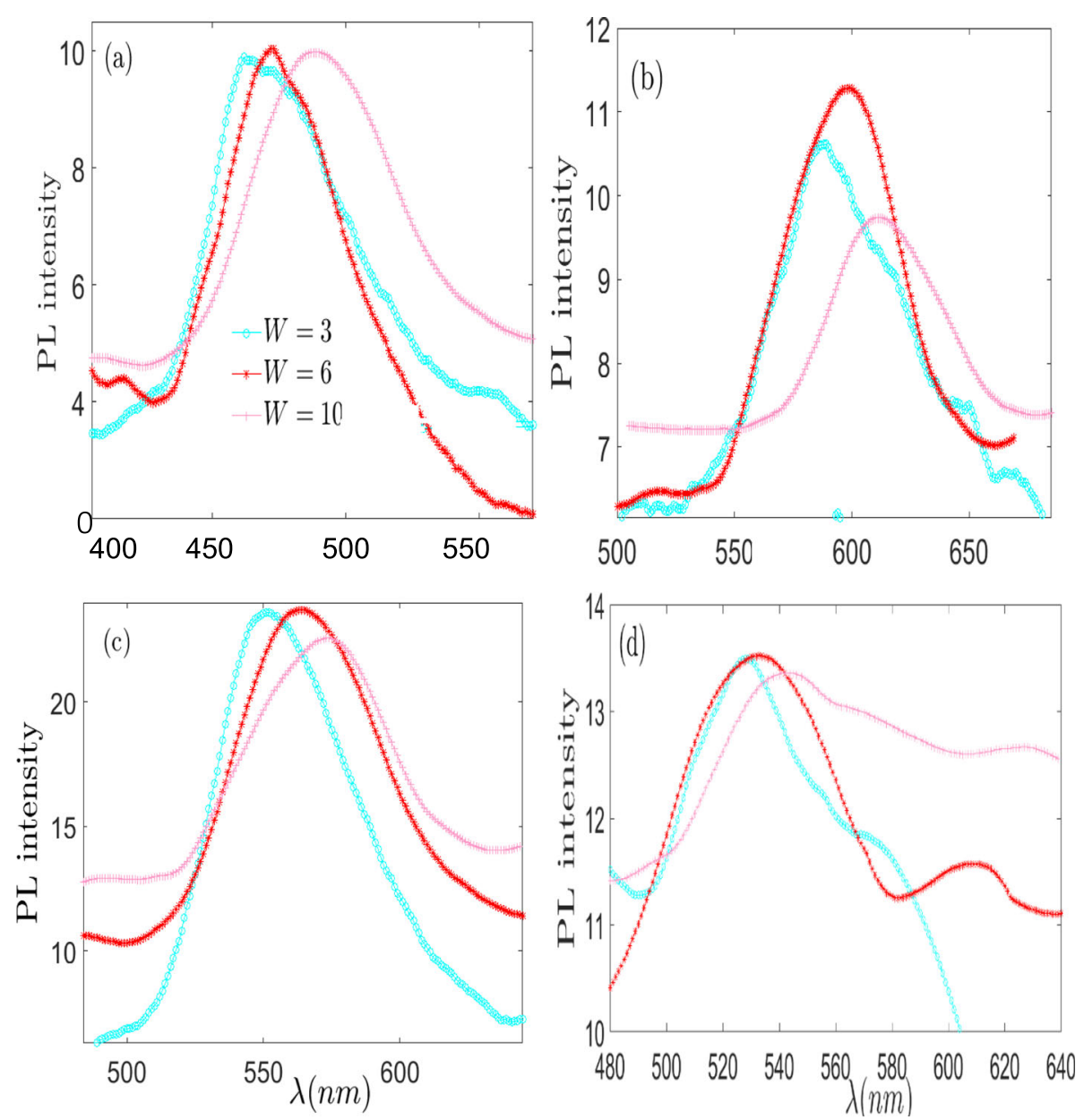

Fig. 3 PL spectrum of QWQDs vs wave length at different W values for a) core $\mathrm{CdS}$, b) core/shell $\mathrm{CdS} / \mathrm{ZnS}, \mathbf{c}) \mathrm{CdS} / \mathrm{ZnS} / \mathrm{CdS}$ and d) $\mathrm{CdS} / \mathrm{ZnS} / \mathrm{CdS} / \mathrm{ZnS}$

slightly red shift with time passing. CdS/ZnS QDs samples have higher stability than $\mathrm{CdS}$ core and retain their PL properties for longer time.

After time focusing, we investigate the QDs size dependence of the absorption and PL spectra. QWQDs emission can be tuned by varying the dot size, which is easily controlled by $W[25,26]$. Particle size of dots in reverse micelle method decreases with the reducing of $W$ values as $\left(1+\frac{15}{r}\right)^{3}-1=\frac{27.5}{W}[12]$, thus it leads to a blue-shift of emission wavelength.

PL photos of QWQDs synthesized at different $W$ values for a) $\mathrm{CdS}$, b) $\mathrm{CdS} / \mathrm{ZnS}, \mathrm{c}) \mathrm{CdS} / \mathrm{ZnS} / \mathrm{CdS}$ and d) $\mathrm{CdS} / \mathrm{ZnS} / \mathrm{CdS} / \mathrm{ZnS}$ are shown in Fig. 3. At higher magnitudes of $W$ parameter, PL spectra of QDs shifts to right hand due to the increase of particle size.

The absorbance spectrums as a function of the $\lambda$ for three different values of $W$ are shown in Fig. 4 that presents how the absorption intensity is dependent on the concentration of a solution. This figure reveals the absorption spectra from two important observations: (a) absorbance decreases with the increase in $\mathrm{W}$ value and core thickness; (b) the absorbance peak gets blue shifted as $W$ increases in which the peak at $\lambda=480 \mathrm{~nm}$ for $W=$ 10 shifts to $\lambda=483 \mathrm{~nm}$ for $W=6$ and $\lambda=486 \mathrm{~nm}$ for $W=$ 3.

Similar performance was achievable for $\mathrm{CdS} / \mathrm{ZnS}$ core/ shell absorbance spectrum (Fig. 5). As shown, increasing of $W$ values corresponds to a red-shift of emission wave length. A red shift of about $25 \mathrm{~nm}$ in the absorption peak was observed. The absorption spectra of $\mathrm{CdS} / \mathrm{ZnS}$ shifted from $515 \mathrm{~nm}$ to $540 \mathrm{~nm}$ due to the $W$ increasing. Moreover, the absorbance of core/shell nanocrystals strongly depends on the thickness of the passivating shell. CdS QDs with the passivation of $\mathrm{ZnS}$ shell shows higher stability of the PL efficiency than a CdS core. Figures 6 and 7 show the absorbance as a function of the emission.

It should be mentioned that the defect emission of $\mathrm{ZnS}$ inner-shell can create both of the green emission 


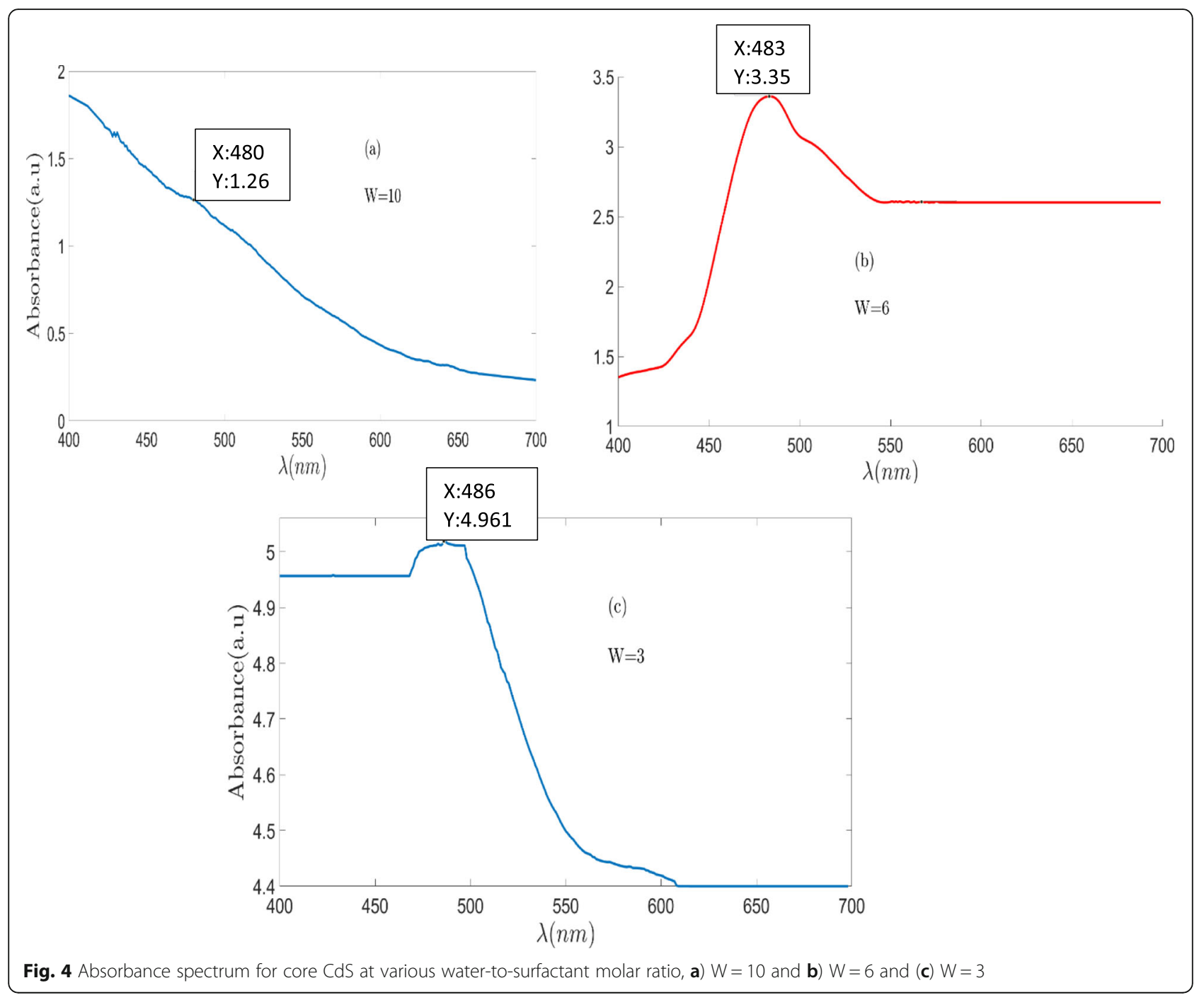

peaked at $\lambda \cong 525 \mathrm{~nm}$ and orange emission at $\lambda \cong 580 \mathrm{~nm}$ $[12,26]$. So, in presented structure, blue emission from core CdS can combine with green and red emission from the shell $\mathrm{ZnS}$ and generates the white light. We manage dot size to study the absorbance, PL intensities and chromaticity coordinates diagram of the output light $[12,27]$.

Absorbance, PL intensity and CIE coordinates for QDs with $\mathrm{W}=6$ and core/ double shell layer structure are shown in Fig. 8. As shown in this figure, water-tosurfactant molar ratio plays an important role in optical properties of QDs emission. In following, we demonstrate how $W$ parameter can manage the current density of QD-LED fabricating with thin and uniform CdS/ZnS/ CdS/ZnS colloidal QDs film.

Different correlated color temperature (CCT) and color rendering index (CRI) values with corresponding CIE (Commission Internationale de l'Eclairage) coordinates are presented in Table 1 . The values of CRI and CCT were calculated according to equations defined by the CIE. The maximum CRI value is 94.88 at a CCT of $1625 \mathrm{~K}$. In addition, one of the CIE coordinates is $(0.3335,0.3464)$ which is close to the standard neutral white light $(0.33,0.33)[28,29]$. Thus, these results indicate that $\mathrm{CdS} / \mathrm{ZnS}$ spherical colloidal quantum dots are promising potential in solid-state lighting for light emitting devices [30].

Figure 9 shows the Current density vs. applied voltage characteristics under an applied voltage of $4 \mathrm{~V}$ for two different QD sizes of LED, one including dots with $W=$ 6 and another with $W=3$. First, the Current gradually increases until $\sim 2 \frac{m A}{c m^{2}}$ and the $\mathrm{J}-\mathrm{V}$ characteristics remain approximately the same for both $\mathrm{W}$ values. Then dot size controls the I-V curves. A comparison of the electrical properties of this QWQD based LED with $W=3$ and that of with varied ratio $W=6$ exhibits that 


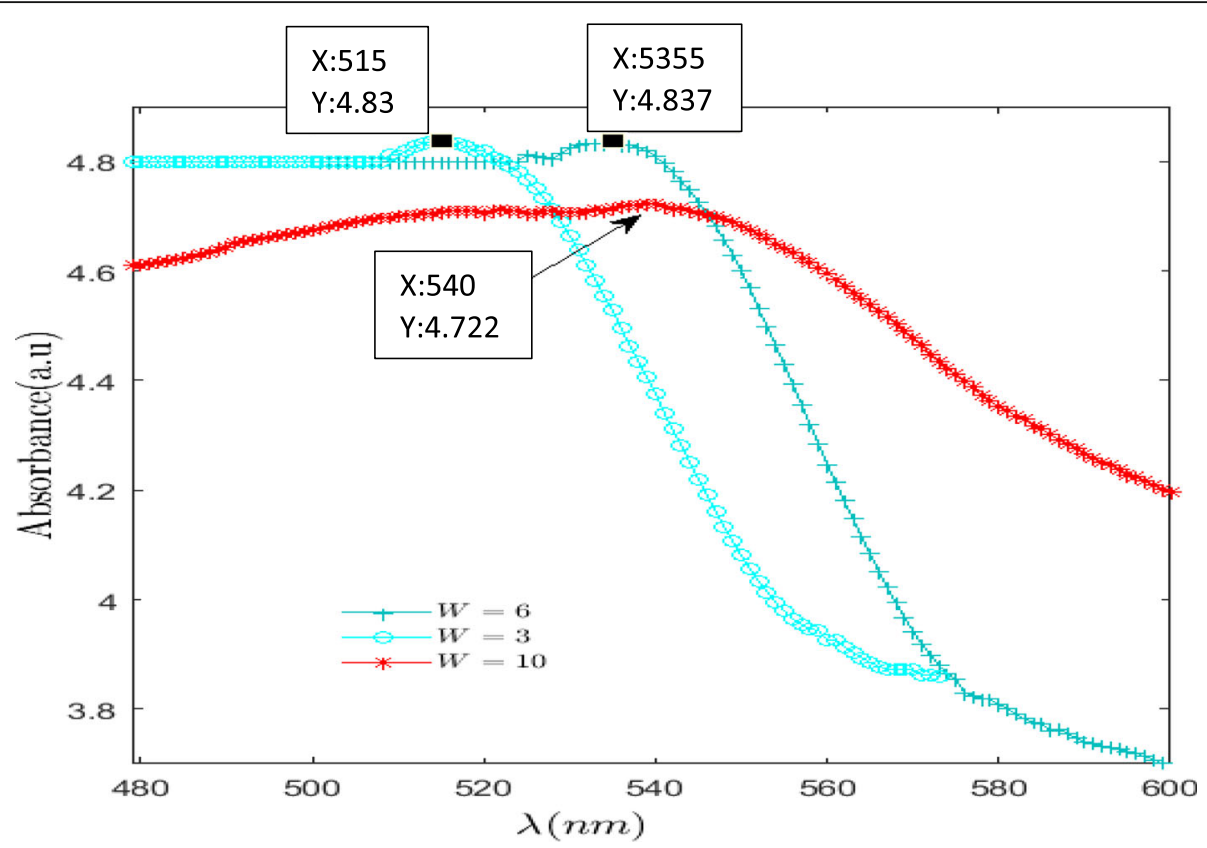

Fig. 5 Absorbance spectrum for CdS/ZnS core/shell when W values decreases from 10, 6 to 3. wave length at two different thicknesses of the $\mathrm{ZnS}$ shell. First we synthesize the core/Shell CdS/ZnS, then we decrease or increase the shell thickness to prepare core/half shell (Fig. $6(\mathrm{~b}))$ or core/double shell (Fig. 7(b)). The change in absorbance peak is determined by the shell thickness and thus the dot size

the QDLED with larger nano particle layer $(W=3)$ has a higher current density. Thus, the increases in the QD size result in increased current density. From the enlarged current density, we can conclude that QD layer with $\mathrm{W}=3$ is superior to that for $\mathrm{W}=6$ in our device structure.

Finally, Fig. 10 presents the electroluminescence (EL) spectra obtained from the fabricated $\mathrm{Cds} / \mathrm{ZnS} / \mathrm{CdS} / \mathrm{ZnS}$ QD-LED for $=3$. This spectrum has two distinct peaks; the blue emission peak at $\lambda \cong 456 \mathrm{~nm}$ due to $\mathrm{CdS}$ and a red emission peak at $\lambda \cong 590 \mathrm{~nm}$ due to $\mathrm{ZnS}$, as we expected.

\section{Conclusion}

In summary, we report the white light emission QWQDs enable us to fabricate the WLED based on the thin and uniform $\mathrm{CdS} / \mathrm{ZnS} / \mathrm{CdS} / \mathrm{ZnS}$ colloidal QD film. Twolayer $\mathrm{CdS} / \mathrm{ZnS}$ as a core/shell QD structure result the
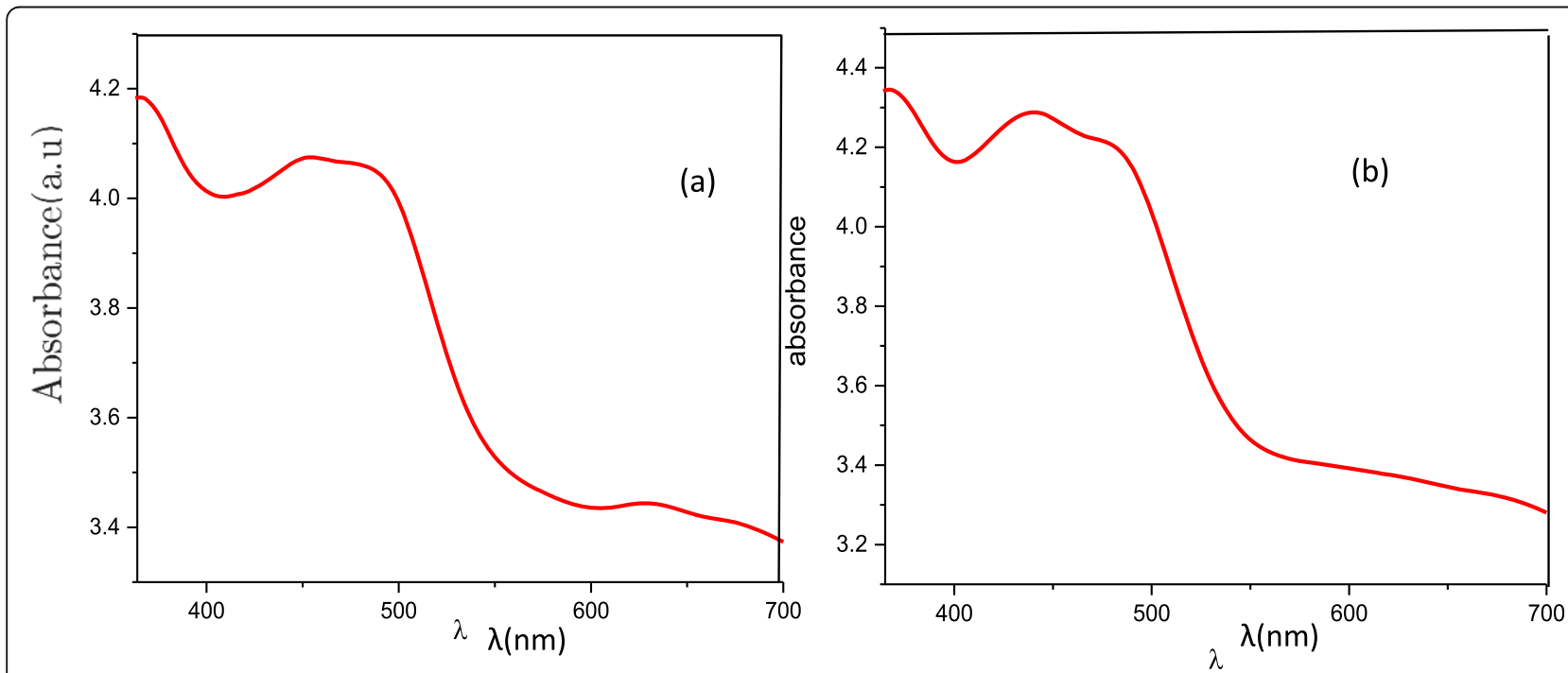

Fig. 6 Absorbance spectra of CdS/ZnS core/shell QDs with different thickness of ZnS shell, a) CdS/ZnS, b) CdS/half ZnS. Here we assume W=5 


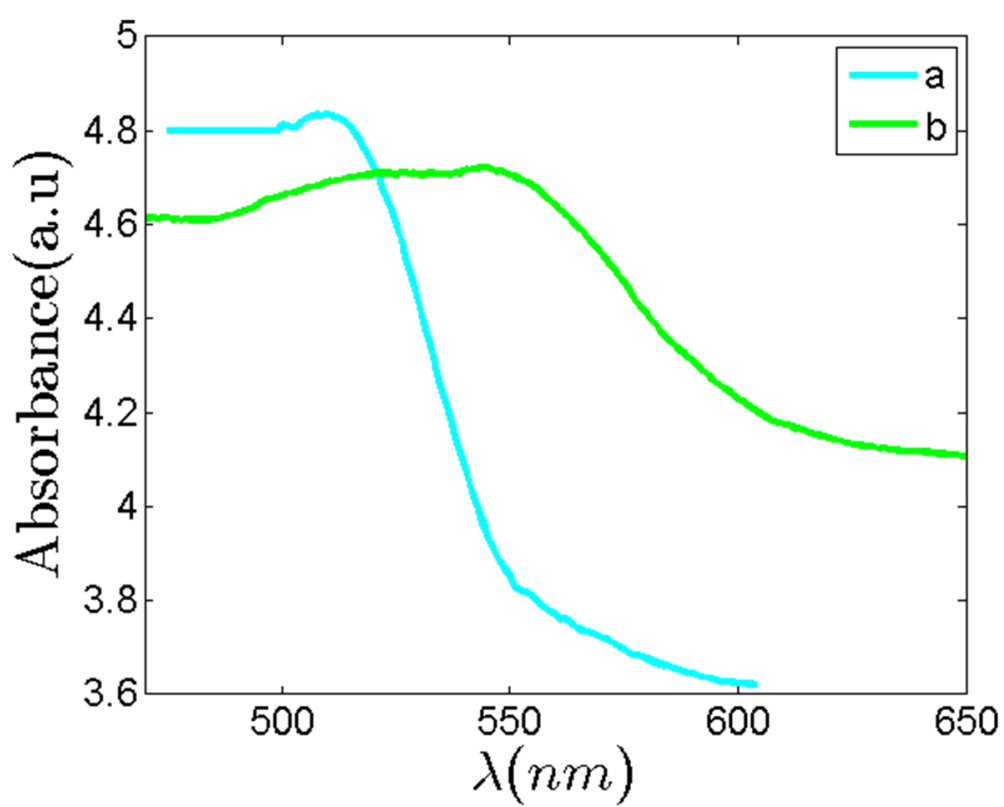

Fig. 7 Absorbance spectra of CdS/ZnS core/shell QDs with different thickness of ZnS shell, a) CdS/ZnS, b) CdS/double ZnS. Here we assume $W=6$ 

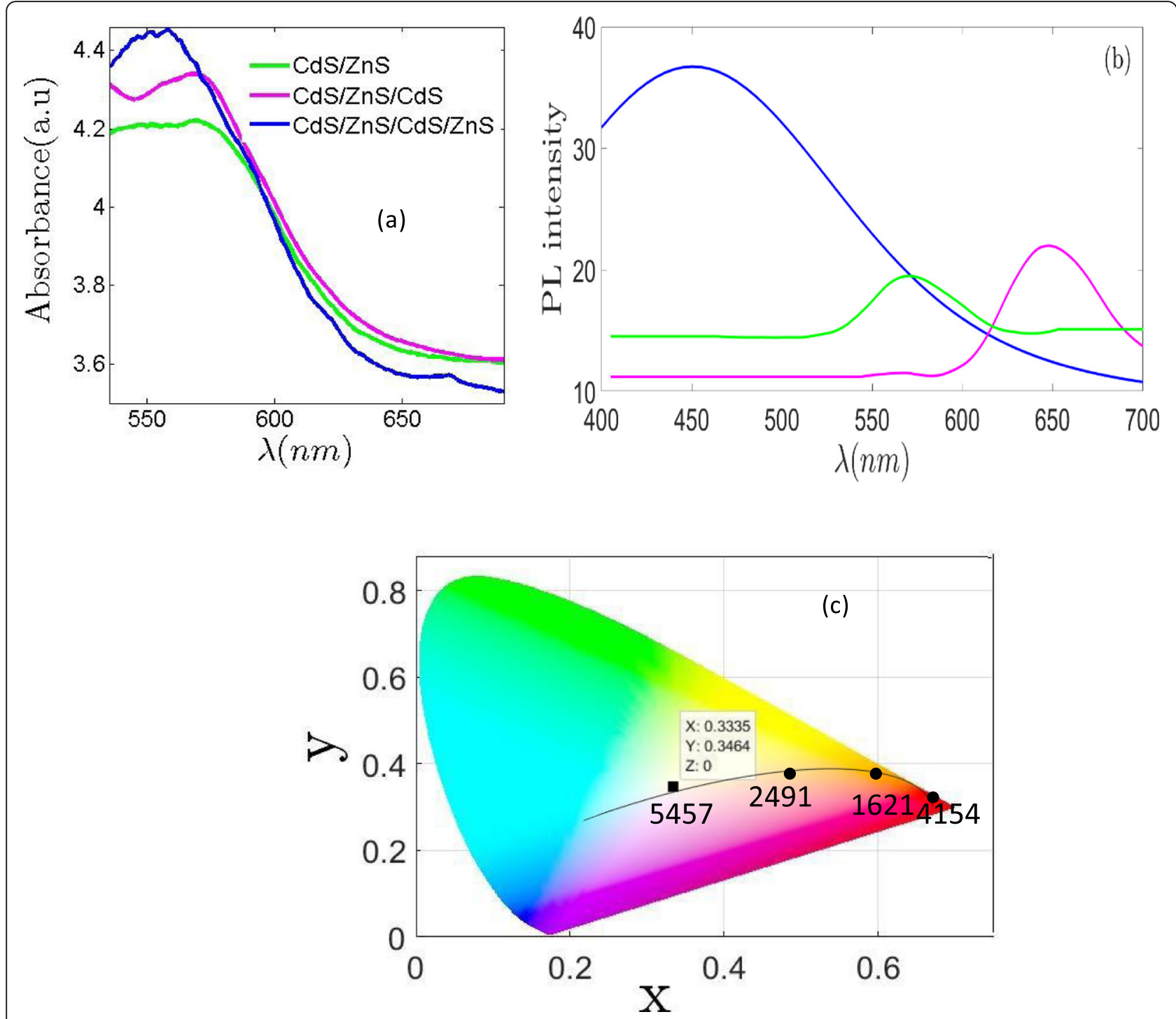

Fig. 8 (a) Absorbance, (b) PL spectra and (c) CIE coordinates of QDs $(W=6)$. The white light emission is obtained from the mixture of blue and green/orange emission originated from core CdS and the inner shell ZnS, respectively. The excitation wavelength is $=400$. The CIE coordinates of this white light emission is $(0.33,0.34)$

Table 1 The values of CIE coordinates, CCT and CRI

\begin{tabular}{llll}
\hline $\mathbf{x}$ & $\mathbf{y}$ & $\mathbf{C C T}(\mathbf{K})$ & $\mathbf{C R I}$ \\
\hline 0.3335 & 0.3464 & 5457 & 91.12 \\
0.4001 & 0.4 & 3695 & 93.29 \\
0.5 & 0.4503 & 2491 & 94.1 \\
0.6001 & 0.3999 & 1625 & 94.88 \\
0.6502 & 0.3001 & 4154 & 92.93 \\
\hline
\end{tabular}




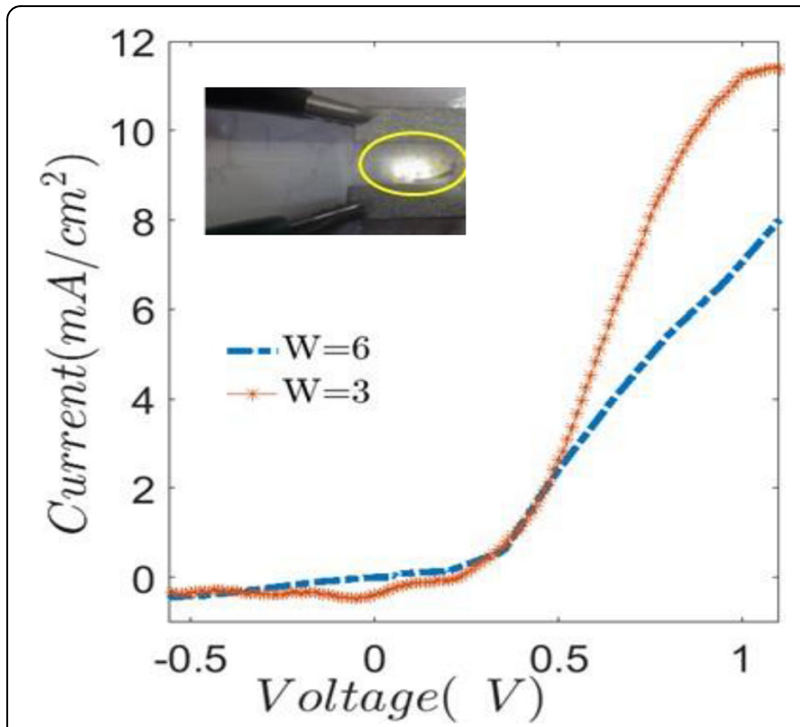

Fig. 9 Current density-voltage (J-V) characteristics for the QD-LEDs with two values of $W$

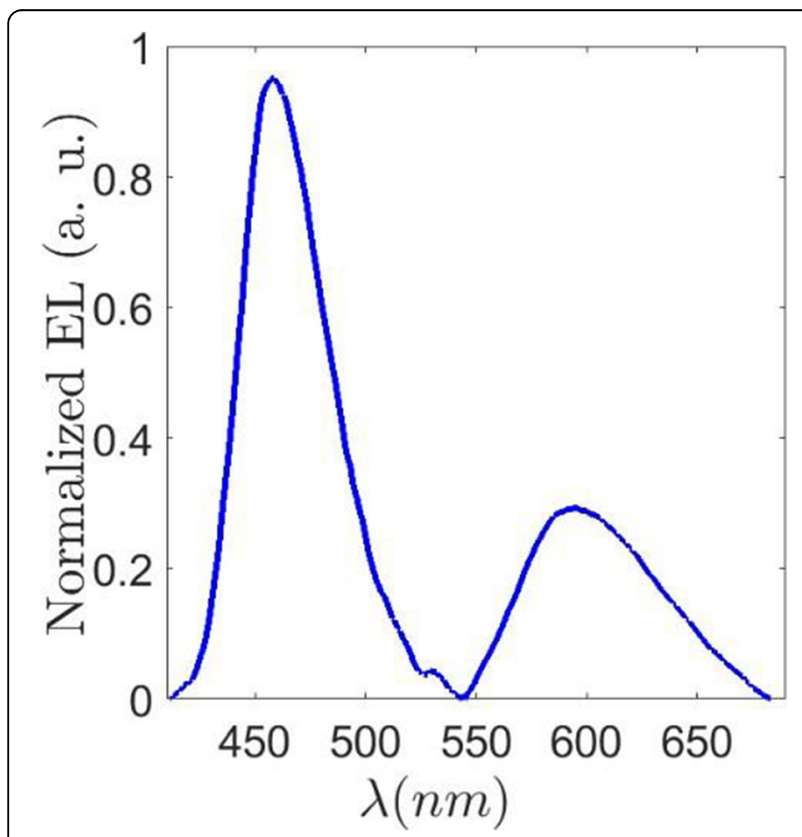

Fig. 10 EL spectra for the fabricated QDLED white light emission in which the blue and green/orange emission originate from $\mathrm{CdS}$ core and $\mathrm{ZnS}$ shell, respectively. Experimental results are shown that the emission properties and the current density critically depend on the water-tosurfactant molar ratio or dots size. We find a blue shift of absorbance and PL spectrums and smaller current density for mentioned core/shell structure at larger dot size.

\section{Acknowledgements}

This research has been supported by Iran National Science Foundation (INSF) No. 95000510.

\section{Authors' contributions}

K. hasanirokh carried out the experiment and fabricated the QDLED sample with support from S. Mohammadi. K. hasanirokh wrote the manuscript. A. Asgari conceived the original idea supervised the project. All authors read and approved the final manuscript.

\section{Funding}

Not applicable.

\section{Availability of data and materials}

Not applicable.

\section{Declarations}

\section{Competing interests}

The authors declare no competing interest.

\section{Author details}

${ }^{1}$ Research Institute for Applied Physics \& Astronomy, University of Tabriz Tabriz 51665-163, Iran. ${ }^{2}$ School of Electrical, Electronic and Computer Engineering, The University of Western Australia, Crawley, WA 6009, Australia.

Received: 30 June 2021 Accepted: 25 November 2021

Published online: 13 December 2021

\section{References}

1. Murray, C.B., Norris, D.J., Bawendi, M.G.: Synthesis and characterization of nearly monodisperse $\mathrm{CdE}$ ( $\mathrm{E}=$ sulfur, selenium, tellurium) semiconductor nanocrystallites. J. Am. Chem. Soc. 115(19), 8706-8715 (1993). https://doi. org/10.1021/ja00072a025

2. Dabbousi, B.O., Rodriguez Viejo, J., Mikulec, F.V., Heine, J.R., Mattoussi, H., Ober, R., Jensen, K.F., Bawendi, M.G.: (CdSe)ZnS Core-Shell Quantum Dots: Synthesis and Characterization of a Size Series of Highly Luminescent Nanocrystallites. J. Phys. Chem. B. 101(46), 9463-9475 (1997). https://doi. org/10.1021/jp971091y

3. Anikeeva, P.O., Halpert, J.E., Bawendi, M.G., Bulovic, V.: Nano Lett. 7, 2196 (2007)

4. Coe-Sullivan, S., Woo, W., Bawendi, M.G., Bulovic, V.: Nature. 420, 800 (2002)

5. Kim, J.H., Lee, K.H., Kang, H.D., Park, B., Hwang, J.Y., Seong Jang, H., Rag Do, Y., Yang, H.: Fabrication of a white electroluminescent device based on bilayered yellow and blue quantum dots. Nanoscale. 7(12), 5363-5370 (2015). https://doi.org/10.1039/C5NR00426H

6. Hee Kim, H., Park, S., Yi, Y., Ick Son, D., Park, C., Kyung Hwang, D., Kook Choi, W. Inverted Quantum Dot Light Emitting Diodes using Polyethylenimine ethoxylated modified ZnO. Sci. Rep. 5(1), 8968 (2015). https://doi.org/10.1038/srep08968

7. Lee, K.H., Han, C.Y., Kang, H.D., Ko, H., Lee, C., Lee, J.H., Myoung, N., Yim, S.Y., Yang, H.: Highly Efficient, Color-Reproducible Full-Color Electroluminescent Devices Based on Red/Green/Blue Quantum Dot-Mixed Multilayer. ACS Nano. 9(11), 10941-10949 (2015). https://doi.org/10.1021/acsnano.5b05513

8. MoslehiMilani, N., Mohadesi, V., Asgari, A.: The effects of temperature dependent recombination rates on performance of InGaN/GaN blue superluminescent light emitting diodes. Phys. E. 71, 64-69 (2015). https:// doi.org/10.1016/j.physe.2015.04.005

9. MoslehiMilani, N., Asgari, A.: The effects of carrier transport phenomena on the spectral and power characteristics of blue superluminescent light emitting diodes. Phys. E. 69, 165-170 (2015). https://doi.org/10.1016/j. physe.2015.01.035 
10. Li, W., Zhao, B., Yao, Y., Gao, M., Sun, K.: Nanoscale. 7, 17231 (2015)

11. Ghosh, T., Prasad, E.: J. Phys. Chem. C. 119, 2733 (2015)

12. Qian, L., Yixing, Y., Changfeng, H., Yuanyuan, C., Ling, C., Ting, Z., Wei, X.: White light emission from quantum well structured quantum dots. Mat. Sci. Eng B. 193, 1-3 (2015). https://doi.org/10.1016/j.mseb.2014.10.013

13. Cai, H., Cheng, L., Xu, F., Wang, H., Xu, W., Li, F.: Fabrication of the heterojunction catalyst BivO4/P25 and its visiblelight photocatalytic activities. R. Soc. open sci. 5 , 180752 (2018)

14. Zhou, F.Q., Fan, J.C., Xu, Q.J., Min, Y.L.: BiVO4 nanowires decorated with CdS nanoparticles as Z-scheme photocatalyst with enhanced $\mathrm{H} 2$ generation. Appl. Catal. B Environ. 201, 77-83 (2017). https://doi.org/10.1016/j.apcatb.2 016.08.027

15. Liu, J., Liu, Y., Liu, N., Han, Y., Zhang, X., Lifshitz, Y.: Sh-T. Lee, J. Zhong, Z. Kang. Science. 347(6225), 970-974 (2015). https://doi.org/10.1126/ science.aaa3145

16. Wu, K., Park, Y.S., Lim, J., Klimov, V.I.: Nat. Nano technol. 12, 1140-1147 (2017)

17. Hasanirokh, K., Asgari, A.: Modeling and studying of white light emitting diodes based on CdS/ZnS spherical quantum dots. Opt. Mater. 81, 129-133 (2018). https://doi.org/10.1016/j.optmat.2018.05.024

18. Ryu, H.Y., Ryu, G.H., Choi, Y.H., Byungin, M.: Modeling and simulation of efficiency droop in GaN-based blue light-emitting diodes incorporating the effect of reduced active volume of InGaN quantum wells. Curr. Appl. Phys. 17(10), ) 1298-) 1302 (2017). https://doi.org/10.1016/j.cap.2017.06.014

19. Takano, T., Mino, T., Sakai, J., Noguchi, N., Tsubaki, K., Hirayama, H.: Deepultraviolet light-emitting diodes with external quantum efficiency higher than $20 \%$ at $275 \mathrm{~nm}$ achieved by improving light-extraction efficiency. Appl. Phys. Express. 10(3), 031002 (2017). https://doi.org/10.7567/APEX.10.031002

20. Song, K.W., Costi, R., Bulovic, V.: Electrophoretic Deposition of CdSe/ZnS Quantum Dots for Light-Emitting Devices. Adv. Mater. 25(10), 1420-1423 (2013). https://doi.org/10.1002/adma.201203079

21. van der Biest, O.O., Vandeperre, L.J.: Electrophoretic deposition of materials, Annu. Rev. Mater. Sci. 29(1), 327-352 (1999). https://doi.org/10.1146/a nnurev.matsci.29.1.327

22. Islam, M.A., Herman, I.P.: Electrodeposition of patterned CdSe nanocrystal films using thermally charged nanocrystals. Appl. Phys. Lett. 80(20), 38233825 (2002). https://doi.org/10.1063/1.1480878

23. Islam, M.A., Xia, Y.Q., Telesca, D.A., Steigerwald, M.L., Herman, I.P.: Controlled Electrophoretic Deposition of Smooth and Robust Films of CdSe Nanocrystals. Chem. Mater. 16(1), 49-54 (2004). https://doi.org/10.1021/ cm0304243

24. Brown, P., Kamat, P.V.: Quantum Dot Solar Cells. Electrophoretic Deposition of CdSe-C60Composite Films and Capture of Photogenerated Electrons withnC60Cluster Shell. J. Am. Chem. Soc. 130(28), 8890-8891 (2008). https:// doi.org/10.1021/ja802810c

25. Yang, H., Holloway, P., Cunningham, G., Schanze, K.S.: CdS:Mn nanocrystals passivated by ZnS: Synthesis and luminescent properties. J. Chem. Phys. 121(20), 10233-10240 (2004). https://doi.org/10.1063/1.1808418

26. Hoener, C.F., Allan, K.A., Bard, A.J., Campion, A., Fox, M.A., Mallouk, T.E., Webber, S.E., White, J.M.: Demonstration of a shell-core structure in layered cadmium selenide-zinc selenide small particles by $\mathrm{x}$-ray photoelectron and Auger spectroscopies. J. Phys. Chem. 96(9), 3812-3817 (1992). https://doi. org/10.1021/j100188a045

27. Markevich, I., Tetyana, S., Bondarenko, V.O.: Quantum Electronics, Optoelectronics. 18, 134 (2015)

28. Zhao, S., Mo, Q., Cai, W., Wang, H., Zang, Z.: Inorganic lead-free cesium copper chlorine nanocrystal for highly efficient and stable warm white light-emitting diodes. Photon. Res. 9(2), 187-192 (2021). https://doi.org/1 $0.1364 /$ PRJ 409398

29. Zhao, S., Chen, C., Cai, W., Li, R., Li, H., Jiang, S., Zang, Z.: Efficiently Luminescent and Stable Lead-free Cs3Cu2CI5@Silica Nanocrystals for White Light-Emitting Diodes and Communication. Adv. Opt. Mater. 9(13), 2100307 (2021). https://doi.org/10.1002/adom.202100307

30. Adhikari, G.C., Vargas, P.A., Zhu, H., Grigoriev, A., Zhu, P.: Tetradic phosphor white light with variable CCT and superlative CRI through organolead halide perovskite nanocrystals. Nanoscale Adv. 1(5), 1791-1798 (2019). https://doi.org/10.1039/C9NA00125E

\section{Publisher's Note}

Springer Nature remains neutral with regard to jurisdictional claims in published maps and institutional affiliations.

\section{Submit your manuscript to a SpringerOpen ${ }^{\circ}$ journal and benefit from:}

- Convenient online submission

- Rigorous peer review

- Open access: articles freely available online

- High visibility within the field

- Retaining the copyright to your article

Submit your next manuscript at $\boldsymbol{\nabla}$ springeropen.com 